\title{
Inhibition of return and attentional control settings
}

\author{
BRADLEY S. GIBSON and JOANNA AMELIO \\ University of Notre Dame, Notre Dame, Indiana
}

\begin{abstract}
In the present study, we used a spatial cuing paradigm in conjunction with a choice identification task to investigate whether exogenous attentional orienting and inhibition of return are affected by attentional control settings. As in previous studies (e.g., Folk, Remington, \& Johnston, 1992), onset- and color-defined targets were crossed with uninformative onset- and color-defined cues. As expected, when the cue-target stimulus onset asynchrony (SOA) was short (i.e., $100 \mathrm{msec}$ ), the results showed that exogenous attentional orienting was contingent on attentional set; attentional capture occurred in response to a particular cue only when the feature that defined the cue also defined the target (Folk et al., 1992). More importantly, when the cue-target SOA was long (i.e., 1,000 msec), the results showed that the occurrence of inhibition of return was also contingent on attentional set, at least partially so; inhibition of return occurred in response to onset cues only when they preceded onset targets. In contrast, inhibition of return never occurred in response to color cues (at a variety of long SOAs). The associations and dissociations that were observed between exogenous attentional orienting and inhibition of return are discussed in terms of posterior and anterior attention networks in the brain (Posner \& Petersen, 1990).
\end{abstract}

Presentation of a brief luminance increment in the visual periphery is known to affect subsequent visual processing in two distinct ways. First, such onsets are thought to elicit a reflexive shift of spatial attention to the stimulated location. Behaviorally, these attention shifts function to facilitate visual processing at the stimulated location, at least when the temporal interval between the initial onset and a subsequent onset target is relatively short (150 msec or less). In contrast, this relatively fast-acting facilitation typically gives way to a slower-acting inhibition that can be observed when the temporal interval between the two onsets is relatively long (greater than $300 \mathrm{msec}$ ). This second, inhibitory, effect has come to be known as inhibition of return (Posner \& Cohen, 1984; Posner, Rafal, Choate, \& Vaughan, 1985).

Although it is commonly believed that abrupt visual onsets have a priviledged status in eliciting both reflexive shifts of covert attention and inhibition of return (see Rafal, 1996; Rafal \& Henik, 1994; and Yantis, 1996, for reviews), more recent investigations into the nature of attentional control suggest that the ability to elicit reflexive shifts of spatial attention may depend in large part on the specific behavioral goals that are induced by the experimental task (Folk, Remington, \& Johnston, 1992; Folk, Remington, \& Wright, 1994; Gibson \& Jiang, 1998; Gibson \& Kelsey, 1998). For instance, Folk et al. (1992) manipulated attentional set by varying the way in which targets were defined. They showed that preceding onset cues that were uninformative about the target's position in the display could capture attention (as evidenced by the fact that reaction times

Correspondence should be addressed to B. S. Gibson, Department of Psychology, University of Notre Dame, Notre Dame, IN 46556 (e-mail: gibson.16@nd.edu).
[RTs] were faster when the cue and target appeared at the same location compared with when they appeared at different locations) only when observers were intentionally looking for the appearance of an onset-defined target. Similarly, they also showed that uninformative color cues could capture attention only when observers were intentionally looking for the appearance of a color-defined target. In contrast, neither type of cue captured attention when the defining feature (i.e., onset or color) of the cue was incongruent with the defining feature of the target. Such findings suggest that reflexive (or exogenous) shifts of attention are ultimately contingent on attentional control settings, which are defined, in part, by the goals and intentions of the observer (see also Gibson \& Kelsey, 1998).

The hypothesis that exogenous attentional orienting is contingent on attentional control settings has helped to establish the conditions under which spatial shifts of attention can be elicited by salient objects and events in the external world. In the present study, we have attempted to extend this hypothesis to the study of inhibition of return. Indeed, an understanding of the various stimulus conditions that lead to the production of inhibition of return, as well as an understanding of the various task conditions that are capable of revealing the effects of this inhibition, have been a central concern of much previous research (see Taylor \& Klein, 1998, for a review). The present study provides an important contribution to the literature by addressing whether the mere appearance of an uninformative luminance increment in the visual periphery is sufficient to cause the occurrence of inhibition of return, or whether such elicitation is modulated by the behavioral goals of the observer. Likewise, the present study also addresses whether inhibition of return can be caused by other stimulus features, such as color, when observers are in the appropriate attentional set. 
In addition, by measuring how both spatial shifts of attention and inhibition of return are affected by attentional set, the present study addresses the question of what is inhibited by inhibition of return. Of particular relevance is the hypothesis that exogenous attention is inhibited from returning to previously attended locations or objects (Posner \& Cohen, 1984). If this hypothesis is correct, attentional control settings should similarly affect both attentional orienting and inhibition of return (ReuterLorenz, Jha, \& Rosenquist, 1996).

Finally, it is also important to note that, as in previous studies of attentional set (Folk et al., 1992; Gibson \& Kelsey, 1998), we have used in all of the experiments reported here a choice identification task to measure the effects of attention and inhibition. Although choice identification tasks have not been widely used in studies of inhibition of return, Pratt, Kingstone, and Khoe (1997; see also Pratt, 1995; cf. Terry, Valdes, \& Neill, 1994) have recently reported the occurrence of inhibition of return when such a task is used. The use of a choice identification task is important because it can help to rule out motorbased explanations, which contend that inhibition of return reflects a bias against responding (as opposed to attending) to previously stimulated locations and therefore is dependent on spatial localization tasks (see Klein \& Taylor, 1994, for a more detailed description of this account).

\section{EXPERIMENT 1}

\section{Method}

Subjects. Forty-eight University of Notre Dame undergraduates participated for course credit. Half of the subjects received the onsettarget condition whereas the other half received the color-target condition. All subjects had normal or corrected-to-normal vision.

Stimuli and Apparatus. The stimuli were very similar to those used in previous studies of attentional control settings (see, e.g., Folk et al., 1992; Gibson \& Kelsey, 1998). Each trial consisted of a series of three displays: a fixation display, a cue display, and a target display. All displays were presented on a black background. The fixation display contained a white (IBM color 15) central fixation cross $\left(0.8^{\circ} \times 0.8^{\circ}\right)$ presented within a dark gray (IBM color 8$)$ box $\left(2.3^{\circ} \times 1.8^{\circ}\right)$. Four identical dark gray boxes also appeared; they were located above, below, to the right, and to the left of the central fixation cross. When measured from the center of each box, these peripheral boxes were placed $5.1^{\circ}$ away from the fixation cross. Two cue conditions were included. In the onset-cue display, the outline contour of one of the four peripheral boxes was made to change. This contour was changed from thin $\left(0.06^{\circ}\right)$ and gray to thick $\left(0.22^{\circ}\right)$ and white; thus, the presentation of the onset cue involved the increase of both the luminance and the width of preexisting contours. ${ }^{1}$ In the color-cue display, all four peripheral boxes were transformed. Three of the four boxes underwent the same transformation that occurred in the onset-cue display (i.e., the outline contours of the peripheral boxes were changed from thin and gray to thick and white), whereas the fourth box was transformed from a thin, gray outline to a thick, red (IBM color 12) outline. It should be noted that, as in other studies of attentional set (Folk et al., 1992; Gibson \& Kelsey, 1998), the luminance of the red and white boxes in the colorcue condition (and of the red and white letters in the color-target condition) were not equated (but see Experiments 3 and 4 below). In particular, the red stimuli appeared dimmer $\left(2.89 \mathrm{~cd} / \mathrm{m}^{2}\right)$ than the white stimuli $\left(26.22 \mathrm{~cd} / \mathrm{m}^{2}\right)$. Finally, two types of target displays were also included. In the onset-target condition, either a white $\mathrm{H}$ or a white $U$ appeared in one of the four peripheral boxes, whereas in the color-target condition, either a red $\mathrm{H}$ or a red $\mathrm{U}$ appeared in one of the four peripheral boxes, and a white distractor letter appeared in each of the three remaining boxes. The three distractor letters were always $E, S$, and $P$. All letters subtended $1.3^{\circ} \times 0.8^{\circ}$ of visual angle. All stimuli were presented on a ZEOS color monitor equipped with a standard VGA videocard. A ZEOS 486 microcomputer recorded the reaction times (RTs) to the nearest millisecond.

Procedure. All trials began with the appearance of the fixation display for $500 \mathrm{msec}$. Observers were instructed to keep their eyes focused on the central fixation cross throughout each trial, although eye movements were not objectively measured. The fixation display was followed by the appearance of one of the two cue displays for $100 \mathrm{msec}$. On half of the trials, an onset cue appeared; on the other half, a color cue appeared. The target display then appeared after a stimulus onset asynchrony (SOA) of either 100 or $1,000 \mathrm{msec}$. Importantly, the location of the cue was uncorrelated with the location of the target letter - that is, the target and cue appeared at the same location on $25 \%$ of the trials and appeared at different locations on the remaining $75 \%$ of the trials. An attentional set for onsets was experimentally induced in half of the subjects by consistently presenting onset-defined targets throughout the duration of the experiment, whereas an attentional set for color was experimentally induced in the other half by consistently presenting color-defined targets. ${ }^{2}$ The targets remained on the screen for $100 \mathrm{msec}$. As in previous studies of attentional set (Folk et al., 1992; Gibson \& Kelsey, 1998), all the subjects performed a speeded-choice identification task in which they had to determine, as quickly and as accurately as possible, which of the two target letters was presented on each trial. The observers responded by pressing either the right or the left shift key on the computer keyboard. Hence, responses were based solely on the identity of the target and were uncorrelated with the location of the target stimulus on the computer screen (see also Pratt et al., 1997).

Each of the 48 subjects completed 32 practice trials and then four blocks of 96 experimental trials. On half of the experimental trials within each block, an onset cue preceded the target display; on the other half, a color cue preceded the target display. In addition, each type of cue preceded the target display by $100 \mathrm{msec}$ on half of the trials within each block and by $1,000 \mathrm{msec}$ on the other half of the trials. Finally, within each of the four SOA $\times$ cue type conditions, the cue appeared at the same location as that of the target on eight trials and at a different location on 24 trials. The order of the trials within each block of experimental trials was determined randomly by the computer for each observer.

\section{Results and Discussion}

Mean correct RTs in each of the onset-target and colortarget conditions are depicted in Figure 1 as a function of SOA, cue type, and cue location; corresponding error rates are listed in Table 1. RTs that were faster than $100 \mathrm{msec}$ occurred on $0.10 \%$ of the trials; these data were excluded from the analyses.

Previous studies have shown that exogenous attentional orienting is contingent on attentional control settings (Folk et al., 1992; Gibson \& Kelsey, 1998). The main focus of this experiment was to determine whether inhibition of return is also contingent on attentional control settings. The effects of attentional orienting should be manifested by faster RTs in the same-location condition than in the different-location condition when SOA is 


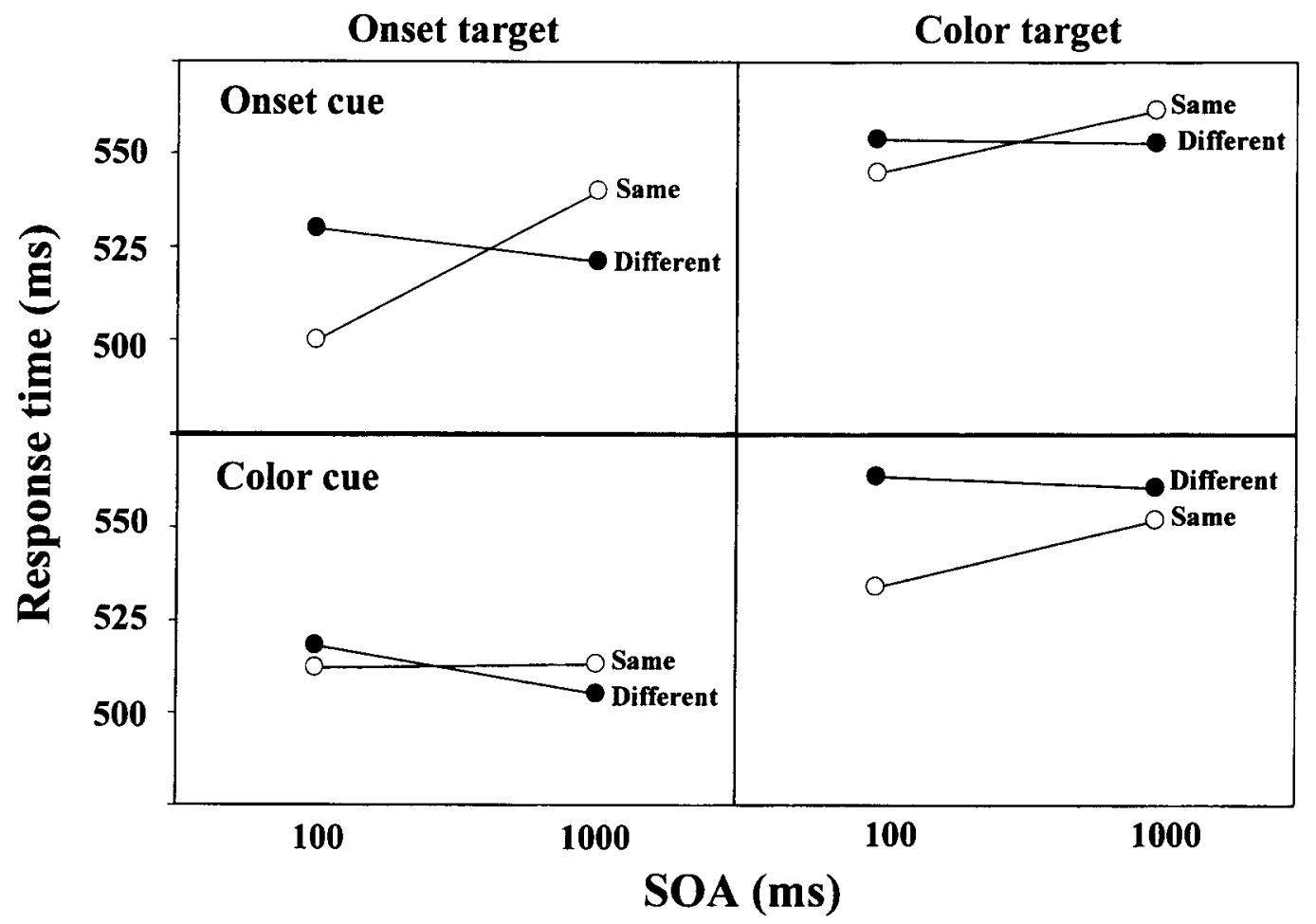

Figure 1. Mean correct reaction time (RT) as a function of stimulus-onset asynchrony (SOA), cue type, and cue location in each of the onset-target and color-target conditions in Experiment 1.

short (i.e., $100 \mathrm{msec}$ ), whereas the effects of inhibition of return should be manifested by slower RTs in the samelocation condition than in the different-location condition when SOA is long (i.e., $1,000 \mathrm{msec}$ ). Hence, if these facilitatory and inhibitory effects are both contingent on attentional set, a significant crossover interaction involving SOA and cue location should be observed only when target type (onset or color) and cue type (onset or color) are the same. In order to assess this prediction, separate repeated measures analyses of variance (ANOVAs) were conducted, with SOA (100 and 1,000 msec) and cue lo-

Table 1

Percent Error Rates As a Function of Cue Type, Stimulus-Onset Asynchrony (SOA, in Milliseconds), and Cue Location in Each of the Onsetand Color-Target Conditions in Experiment 1

\begin{tabular}{|c|c|c|c|}
\hline \multirow[b]{2}{*}{ Cue Type } & \multirow[b]{2}{*}{ SOA } & \multicolumn{2}{|c|}{ Cue Location } \\
\hline & & Same & Different \\
\hline \multicolumn{4}{|c|}{ Onset Target } \\
\hline Onset & 100 & 3.13 & 3.60 \\
\hline & 1,000 & 3.13 & 2.21 \\
\hline Celor & 100 & 4.00 & 3.19 \\
\hline & 1,000 & 2.78 & 2.97 \\
\hline \multicolumn{4}{|c|}{ Color Target } \\
\hline Onset & 100 & 4.34 & 4.52 \\
\hline & 1,000 & 4.52 & 3.38 \\
\hline Color & 100 & 3.65 & 6.56 \\
\hline & 1,000 & 2.44 & 3.77 \\
\hline
\end{tabular}

cation (same location and different location) as the two within-subjects factors, in each of the four target type $x$ cue type conditions. To facilitate discussion, all effects reported as significant in this article occurred with $p<$ .05 or less. Moreover, all analyses in this article focused on mean correct RTs, since error rates tended to follow the same pattern as that for RTs; therefore, unless otherwise noted, none of the analyses suggested a speedaccuracy tradeoff.

To establish the validity of the present paradigm, we first sought to establish the occurrence of the predicted SOA $\times$ cue location interaction when both the target and the cue were defined by onset. This particular combination of target and cue displays can serve to establish the validity of the present paradigm because both the occurrence of early facilitation (e.g., Folk et al., 1992) and late inhibition (e.g., Pratt et al., 1997) have been previously observed, albeit separately, under these conditions. As expected, there was a significant SOA $\times$ cue location interaction with our mean correct RTs when both the target and the cue were defined by onset $[F(1,23)=43.36$, $\left.M S_{\mathrm{e}}=328.90\right]$. There was a significant $30-\mathrm{msec}$ facilitatory effect observed in the 100-msec SOA condition $\left[F(1,23)=27.55, M S_{\mathrm{e}}=386.52\right]$ that later gave way to a significant $19-\mathrm{msec}$ inhibitory effect in the $1,000-\mathrm{msec}$ SOA condition $\left[F(1,23)=14.04, M S_{\mathrm{e}}=307.24\right]$. Hence, the present paradigm appears to be capable of detecting the occurrence of both early facilitation and late inhibition under conditions in which they are expected to occur. 
The next question we considered was whether inhibition of return could be established by onset cues even when observers were set for color (as in the color-target condition). The results suggest that, like attentional orienting, inhibition of return elicited by onset cues can be modulated by attentional set. As can be seen in Figure 1, there was a small (nonsignificant) amount of facilitation $(9 \mathrm{msec})$ at the short SOA $\left[F(1,23)=1.90, M S_{\mathrm{e}}=540.53\right]$ and a small (nonsignificant) amount of inhibition ( $9 \mathrm{msec}$ ) at the long SOA $\left[F(1,23)=2.65, M S_{\mathrm{e}}=333.43\right]$; the critical SOA $\times$ cue location interaction failed to achieve significance in the onset-cue/color-target condition $\left[F(1,23)=3.20, M S_{\mathrm{e}}=597.17\right]$. In addition, the conclusion that onset cues produced a different pattern of results when they preceded color-defined targets compared with when they preceded onset-defined targets was also supported by an ANOVA that evaluated the effects of SOA and cue location across these two target conditions. In particular, the critical target type $\times$ SOA $\times$ cue location interaction was found to be significant $[F(1,46)=$ $\left.6.19, M S_{\mathrm{e}}=463.03\right]$.

Given that onset-induced attentional orienting and onset-induced inhibition of return appeared to be similarly influenced by attentional control settings, we considered whether inhibition of return could be induced by color cues. Although previous research has shown that an early facilitation effect can be induced by color cues, at least when the target is also defined by color (Folk et al., 1992), it is currently unknown whether these stimulus conditions can also elicit inhibition of return. In fact, there was a significant SOA $\times$ cue location interaction observed with mean correct RTs when both the target and the cue were defined by color $\left[F(1,23)=4.63, M S_{\mathrm{e}}=551.65\right]$; however, as can be seen in Figure 1, the pattern of results reflected in this interaction does not indicate the signature crossover interaction that is characteristic of early facilitation and late inhibition of return. Rather, the SOA $X$ cue location interaction observed in the color-cue/ color-target condition merely reflects the dissipation of facilitation at the long $(1,000-\mathrm{msec}) \mathrm{SOA}$. In particular, the significant 30-msec facilitatory effect observed in the 100msec SOA condition $\left[F(1,23)=9.61, M S_{\mathrm{e}}=1,108.35\right]$ shrank to a nonsignificant 10 -msec facilitatory effect in the $1,000-\mathrm{msec}$ SOA condition $\left[F(1,23)=1.40, M S_{\mathrm{e}}=\right.$ 718.42 ]. These findings suggest that although the color cue is capable of summoning attention when it is consistent with the defining features of the target, it is not capable of eliciting inhibition of return. Indeed, the overall pattern of results observed across SOA and cue location in the color-cue/color-target condition was found to be significantly different from the overall pattern of results observed across SOA and cue location in the standard onsetcue/onset-target condition $\left[F(1,46)=5.39, M S_{\mathrm{e}}=440.27\right]$ for the target type $\times$ SOA $\times$ cue location interaction.

Finally, as expected, color cues were also incapable of eliciting either exogenous attentional orienting or inhibition of return when these cues preceded onset-defined targets. The critical SOA $\times$ cue location interaction failed to achieve significance in the color-cue/onset-target condition $\left[F(1,23)=2.96, M S_{\mathrm{e}}=406.36\right]$. In addition, the overall pattern of results observed across SOA and cue location in the color-cue/onset-target condition once again differed significantly from the overall pattern of results observed across SOA and cue location in the standard onset-cue/onset-target condition $[F(1,23)=11.47$, $\left.M S_{\mathrm{e}}=312.72\right]$ for the target type $\times$ SOA $\times$ cue location interaction.

In summary, the results of Experiment 1 suggest that onset cues can cause inhibition of return in the onsettarget condition, but not in the color-target condition. In contrast, inhibition of return failed to be elicited by color cues in either target condition. Hence, the results of Experiment 1 are consistent with the notion that the occurrence of onset-induced inhibition of return is contingent on an attentional set for onset, and that inhibition cannot be induced by color. In the remainder of this article, the validity of this apparent contingency is explored in greater detail.

\section{EXPERIMENT 2}

The findings obtained in the onset-cue/color-target condition of Experiment 1 were consistent with the notion that the occurrence of onset-induced inhibition of return is contingent on an attentional set for onset. However, it is also possible that onset-induced inhibition of return was generated in both target conditions, but that it only showed its effects in the onset-target condition. Indeed, the target displays were physically different across the two target conditions. In particular, four letters appeared in the color-target condition, whereas only one letter appeared in the onset-target condition. Thus, the ability to observe onset-induced inhibition of return might depend on the number of elements that appear in the target display (see, e.g., Gibson \& Egeth, 1994; Pratt et al., 1997). To address this concern, an additional experiment was conducted in which the onset and color cues that were shown in Experiment 1 were factorially combined with two types of color-target displays. On half of the trials, the color-target display was identical to the colortarget display used in Experiment 1; on the other half of the trials, the color-target display consisted of only a single red letter. Note that even though the number of elements in the target display could vary randomly from trial to trial, the target letter was consistently defined as the only red letter present in the display. For this reason, it was assumed that observers would maintain a set for red in this experiment, and in fact, they were explicitly encouraged to do so. If the effects of onset-induced inhibition of return are affected by the number of display elements, the amount of inhibition observed in the red-target-alone condition (i.e., one red target letter) should be significantly greater than the amount that would be observed in the red-singleton condition (i.e., one red target letter presented among three white distractor letters). In contrast, inhibition of return should not occur in either target con- 
dition when color cues are presented before the target display since such cues failed to cause inhibition in Experiment 1 in either the onset-target condition (in which case only a single element appeared in the target display) or the color-target condition (in which case four elements appeared in the target display).

\section{Method}

Subjects. Twenty-four University of Notre Dame undergraduates participated for course credit. All subjects had normal or correctedto-normal vision.

Stimuli and Apparatus. The fixation and cue displays used in Experiment 2 were identical to those used in Experiment 1; the color-target condition used in Experiment 2 was also identical to that used in Experiment 1, though here it will be referred to as the red-singleton condition. In addition, the onset-target condition will now be referred to as the red-target-alone condition because the color of the single target letter was changed from white to red in this experiment.

Procedure. Two major procedural changes were made. First, because the main interest of Experiment 2 concerned inhibition of return, only the long $(1,000-\mathrm{msec})$ SOA condition was shown. Second, each observer was shown both the single-red and red-singleton conditions. As in the color-target condition of Experiment 1, observers were instructed to use color as a way of locating the target. The total number of practice and experimental trials in Experiment 2 was the same as in Experiment 1. However, within each block of experimental trials, the red-target-alone display appeared on half of the trials, and the red-singleton target display appeared on the other half. Each of these target displays was preceded an equal number of times by onset and color cues. Within each of the four cue type $\times$ target type conditions, the cue and target appeared at the same location on 8 trials, and they appeared at different locations on 24 trials. The order of the trials within each block of experimental trials was determined randomly by the computer for each observer.

\section{Results and Discussion}

Mean correct RTs and percent error rates in each of the red-target-alone and red-singleton conditions are listed in Table 2 as a function of cue type and cue location. RTs faster than $100 \mathrm{msec}$ occurred on $0.02 \%$ of the trials. As in Experiment 1, these data were excluded from the analyses.

Separate ANOVAs were performed in the two cue type conditions, with cue location and target type (red target alone vs. red singleton) as the two within-subjects factors. With respect to onset cues, there was a main effect of tar-

Table 2

Mean Correct Reaction Times and Percent Error Rates As a Function of Cue Type and Cue Location in Each of the Single-Red and Red-Singleton Conditions in Experiment 2

\begin{tabular}{|c|c|c|c|c|c|c|}
\hline \multirow[b]{3}{*}{ Cue Type } & \multicolumn{6}{|c|}{ Cue Location } \\
\hline & \multicolumn{2}{|c|}{ Same } & \multicolumn{2}{|c|}{ Different } & \multicolumn{2}{|c|}{ Same-Different } \\
\hline & $M$ & $\% \mathrm{E}$ & $M$ & $\% \mathrm{E}$ & $M$ & $\% \mathrm{E}$ \\
\hline \multicolumn{7}{|c|}{ Red Target Alone } \\
\hline Onset & 552 & 2.25 & 550 & 2.33 & 2 & -0.08 \\
\hline Color & 544 & 1.40 & 549 & 1.69 & -5 & -0.29 \\
\hline \multicolumn{7}{|c|}{ Red Singleton Target } \\
\hline Onset & 569 & 2.09 & 570 & 3.03 & -1 & -0.94 \\
\hline Color & 557 & 2.27 & 575 & 2.90 & -18 & -0.63 \\
\hline
\end{tabular}

get type $\left[F(1,23)=17.87, M S_{\mathrm{e}}=449.32\right]$ indicating that RTs were significantly faster (by $18 \mathrm{msec}$ ) when only a single target letter was shown (as in the red-targetalone condition) compared with when the target letter was accompanied by three distractors (as in the red-singleton condition). More importantly, however, neither the main effect of cue location $(F<1)$ nor the cue location $\times$ target type interaction $(F<1)$ was found to be significant. As can be seen in Table 2, RTs were approximately equal in the same-location and different-location conditions, regardless of how many letters appeared in the target display. The red-target-alone display used in this experiment was almost identical to the onset-target condition used in Experiment 1 (with the sole exception being that the target letter appeared red instead of white); however, an ANOVA to compare the effects of cue location across the two experiments showed that the amount of inhibition in the onset-cue/onset-target condition of Experiment $1(19 \mathrm{msec})$ was significantly larger than it was in the onset-cue/red-target-alone condition of Experiment 2 $\left[F(1,46)=4.94, M S_{\mathrm{e}}=343.93\right]$. A similar result was also obtained when the onset-cue/onset-target condition of Experiment 1 was compared with the onset-cue/redsingleton condition of Experiment $2[F(1,46)=7.18$, $\left.M S_{\mathrm{e}}=339.94\right]$. Hence, the decrease in inhibition that was observed in Experiment 2 when an onset cue preceded a color target appears to have been due to attentional control settings, rather than to some aspect of the measuring task such as the number of letters that appeared in the target display (although this variable may still play a role when onset cues precede onset targets; see, e.g., Gibson \& Egeth, 1994; Pratt et al., 1997).

In addition, the results obtained in the color-cue condition were also consistent with those obtained in Experiment 1 . As in the onset-cue condition, there was main effect of target type $\left[F(1,23)=7.98, M S_{\mathrm{e}}=1,093.33\right]$, which once again indicates that RTs were significantly faster (by $19 \mathrm{msec}$ ) when only a single target letter was shown than when the four letters were shown. However, as in Experiment 1, there was little evidence that inhibition of return could be induced by color cues. In fact, RTs tended to be faster in the same-location condition than in the different-location condition, regardless of how many letters appeared in the target display. However, neither the main effect of cue location $\left[F(1,23)=2.37, M S_{\mathrm{e}}=\right.$ $1,275.89]$ nor the cue location $\times$ target type interaction $\left[F(1,23)=1.55, M S_{\mathrm{e}}=560.29\right]$ achieved significance in Experiment 2.

\section{EXPERIMENT 3}

The failure to find significant amounts of facilitation (at short SOAs) or inhibition (at long SOAs) when uninformative color cues preceded onset-defined targets in Experiment 1 is consistent with the hypothesis that the elicitation of inhibition of return is contingent on attentional set (at least for onset). However, note that there was a large luminance difference between the red and 
white boxes in the color-cue display. In particular, the red-singleton box appeared dimmer than the three white boxes. Such a difference might have been relevant in the onset-target condition, because observers were set to detect a change in luminance in this condition. Thus, the difference in luminance between the red and white boxes in the color-cue display might not have been optimal for observing an effect of the red singleton in this condition, because color and luminance might have been operating in different ways (i.e., attention may have been attracted to the odd color and also to one of the bright boxes). Accordingly, in Experiment 3 we attempted to replicate the findings observed in the onset-target condition of Experiment 1 by using new color cues whose elements were more similar in brightness across the display.

\section{Method}

Subjects. Sixteen University of Notre Dame undergraduates participated for course credit. All subjects had normal or corrected-tonormal vision.

Stimuli and Apparatus. The stimuli were identical to those used in the onset-target condition of Experiment 1, except that the white boxes in the color-cue display were changed to blue (IBM color 9). This change was made in order to eliminate the large luminance difference between the red and white stimuli that had been used in Experiment 1. In Experiment 3, the luminance of the blue boxes $\left(2.57 \mathrm{~cd} / \mathrm{m}^{2}\right)$ was very similar to the luminance of the single red box $\left(2.89 \mathrm{~cd} / \mathrm{m}^{2}\right)$. The onset cues (and targets) remained unchanged.

Procedure. The procedure was identical to that of Experiment 1.

\section{Results and Discussion}

Mean correct RTs and percent error rates in the onsettarget condition are listed in Table 3 as a function of SOA, cue type, and cue location. RTs that were faster than 100 msec occurred on $0.03 \%$ of the trials. These data were excluded from the analyses.

Separate ANOVAs were performed on the two cue type conditions, with SOA and cue location as the two withinsubjects factors. With respect to onset cues, there was only a significant SOA $\times$ cue location interaction $[F(1,15)=$ 18.97, $M S_{\mathrm{e}}=374.10$ ]. As expected, RTs were $21 \mathrm{msec}$ faster in the same-location condition than in the differentlocation condition at the short SOA $[F(1,15)=14.55$, $\left.M S_{\mathrm{e}}=252.66\right]$, which indicates that a significant facilitation effect occurred. In contrast, RTs were $20 \mathrm{msec}$ slower in the same-location condition than in the differentlocation condition at the long SOA $[F(1,15)=7.61$, $\left.M S_{\mathrm{e}}=450.18\right]$, which indicates that a significant inhib-

Table 3

Mean Correct Reaction Times and Percent Error Rates As a Function of Cue Type, Stimulus-Onset Asynchrony

(SOA, in Milliseconds), and Cue Location in Experiment 3

\begin{tabular}{|c|c|c|c|c|c|c|c|}
\hline \multirow[b]{3}{*}{ Cue Type } & \multirow[b]{3}{*}{ SOA } & \multicolumn{6}{|c|}{ Cue Location } \\
\hline & & \multicolumn{2}{|c|}{ Same } & \multicolumn{2}{|c|}{ Different } & \multicolumn{2}{|c|}{ Same-Different } \\
\hline & & $M$ & $\% \mathrm{E}$ & $M$ & $\% \mathrm{E}$ & $M$ & $\% \mathrm{E}$ \\
\hline \multirow[t]{2}{*}{ Onset } & 100 & 513 & 2.09 & 534 & 1.83 & $-2 !$ & 0.26 \\
\hline & 1,000 & 552 & 2.35 & 532 & 2.27 & 20 & 0.08 \\
\hline \multirow[t]{2}{*}{ Color } & 100 & 518 & 2.08 & 518 & 3.48 & 0 & -1.40 \\
\hline & 1,000 & 508 & 3.39 & 524 & 1.92 & -16 & 1.42 \\
\hline
\end{tabular}

itory effect occurred. The findings obtained in the onsetcue/onset-target condition, therefore, replicate the results that were obtained in the onset-cue/onset-target condition of Experiment 1.

Of greater concern was whether the pattern of results obtained in the color-cue condition of Experiment 3 would reveal facilitation (at the short SOA) and inhibition (at the long SOA). As in Experiment 1, the SOA $\times$ cue location interaction failed to reach significance $[F(1,15)=$ 3.30, $\left.M S_{\mathrm{e}}=279.77\right]$, as did both the main effect of SOA and the main effect of cue location $[F(1,15)=0.09$, $M S_{\mathrm{e}}=908.90 ; F(1,15)=3.10, M S_{\mathrm{e}}=343.19$, respectively]. As can be seen in Table 3, there was no facilitation at the short SOA and no inhibition at the long SOA; in fact, RTs were significantly faster (by $16 \mathrm{msec}$ ) in samelocation condition than in the different-location condition at the long SOA $\left[F(1,15)=8.88, M S_{\mathrm{e}}=223.50\right]$. This finding was unexpected and may reflect a speed-accuracy tradeoff, because error rates were also higher in the samelocation condition (3.39\%) than in the different-location condition (1.92\%), although this difference in error rate did not attain significance in the present experiment $\left[F(1,15)=2.33, M S_{\mathrm{e}}=7.47, p>.10\right]$. At any rate, the present results obtained in the color-cue/onset-target condition certainly do not show the expected pattern of early facilitation and late inhibition that had been observed in the onset-cue/onset-target condition $[F(1,15)=27.89$, $\left.M S_{\mathrm{e}}=235.53\right]$ for the target type $\times$ SOA $\times$ cue location interaction. Therefore, the failure to observe significant amounts of facilitation and inhibition in the color-cue condition of Experiment 1 cannot be attributed to luminance differences between the different-colored display elements.

\section{EXPERIMENT 4}

Another important finding observed in Experiment 1 was the failure to observe significant amounts of inhibition in the color-cue/color-target condition, despite the fact that significant amounts of facilitation in this condition were observed. These two findings are important because they appear to represent a dissociation between the occurrence of attentional orienting and the occurrence of inhibition of return; consequently, these findings may be inconsistent with the notion that inhibition of return reflects the inhibition of exogenous attention. Of course, the conclusion that color cues do not cause inhibition of return was weakened by the inclusion of only a single long SOA condition in Experiment 1 (though significant amounts of inhibition of return were observed at this lone SOA in the onset-cue/onset-target condition). In Experiment 4 , we attempted to address this concern by including a wider range of SOAs in the color-cue/color-target condition. In addition to the short $(100-\mathrm{msec}) \mathrm{SOA}$, three longer SOAs of $700,1,100$, and $1,500 \mathrm{msec}$ were included. If color cues were capable of generating inhibition of return in this choice identification task when observers were set for color targets, its effects should be more 
likely to be observed at one or more of the long SOAs that were used in this experiment.

\section{Method}

Subjects. Eighteen University of Notre Dame undergraduates participated for course credit. All subjects had normal or correctedto-normal vision.

Stimuli and Apparatus. The stimuli were identical to those used in the color-cue/color-target condition of Experiment 1, the sole exception was that all the white stimuli (i.e., the three white boxes in the cue display and the three white distractor letters in the target display) that had been used in Experiment 1 appeared blue (IBM color 9), as in Experiment 3.

Procedure. Two major procedural changes were made in Experiment 4 . First, only the color-cue/color-target condition was included. Second, the number of cue-target SOA conditions was increased. The cue-target SOA was randomly determined to be either $100,700,1,100$, or $1,500 \mathrm{msec}$ on each trial. The total number of practice and experimental trials was the same as in Experiment 1. Within each block of experimental trials, each of the four SOA conditions appeared equally often. Within each of the four SOA conditions, the cue and target appeared at the same location on 8 trials, and they appeared at different locations on 24 trials. The order of the trials within each block of experimental trials was determined randomly by the computer for each observer.

\section{Results and Discussion}

Mean correct RTs and percent error rates in the colortarget condition are listed in Table 4 as a function of SOA and cue location. RTs faster than $100 \mathrm{msec}$ occurred on $0.08 \%$ of the trials. These data were excluded from the analyses.

An ANOVA with SOA and cue location as the two within-subjects factors was performed in order to evaluate whether the facilitation expected at the shortest SOA would be replaced by inhibition at one or more of the longer SOAs. Although the SOA $\times$ cue location interaction did attain marginal significance $[F(3,51)=2.68$, $\left.M S_{\mathrm{e}}=322.52, p=.056\right]$, the pattern of results indicated that the amount of facilitation observed at the shortest SOA at $30 \mathrm{msec}\left[F(1,17)=51.23, M S_{\mathrm{e}}=131.77\right]$ was greater than the amount of facilitation that had been observed at any of the longer SOAs (which ranged from 5 to $10 \mathrm{msec}$; all $p s>.05$ ). Thus, the results of this experiment corroborate the results of Experiment 1. Together, these findings suggest that although color cues are capable of causing an attentional shift when observers are set for color, such cues do not appear to be capable of causing inhibition of return.

\section{Table 4}

Mean Correct Reaction Times and Percent Error Rates As a Function of Stimulus-Onset Asynchrony (SOA) and Cue Location in Experiment 4

\begin{tabular}{|c|c|c|c|c|c|c|}
\hline \multirow[b]{3}{*}{ SOA (msec) } & \multicolumn{6}{|c|}{ Cue location } \\
\hline & \multicolumn{2}{|c|}{ Same } & \multicolumn{2}{|c|}{ Different } & \multicolumn{2}{|c|}{ Same-Different } \\
\hline & $M$ & $\% \mathrm{E}$ & $M$ & $\% \mathrm{E}$ & $M$ & $\% \mathrm{E}$ \\
\hline 100 & 525 & 2.78 & 552 & 3.40 & -27 & -0.62 \\
\hline 700 & 537 & 1.16 & 542 & 2.41 & -5 & -1.25 \\
\hline 1,100 & 525 & 3.49 & 534 & 3.41 & -9 & 0.08 \\
\hline 1,500 & 522 & 1.63 & 532 & 2.09 & -10 & -0.46 \\
\hline
\end{tabular}

\section{GENERAL DISCUSSION}

In the present study, we used a spatial cuing paradigm in conjunction with a choice identification task to investigate the relation between inhibition of return and attentional control settings. The first issue we addressed was whether the mere appearance of an uninformative luminance increment in the visual periphery would be sufficient to cause inhibition of return, or whether such elicitation would be modulated by the behavioral goals of the observer. The present study provides strong evidence that the generation of inhibition by preceding onset cues does in fact depend on attentional control settings. This was shown in Experiment 1, in which significant amounts of inhibition were observed when onset cues preceded onset targets but not when they preceded color targets. Moreover, in Experiment 2, we showed that the inability of onset cues to cause inhibition in the color-target condition did not depend on differences in the number of elements appearing in the onset-target and color-target conditions, since reliable amounts of inhibition failed to be observed in the color-target condition, regardless of whether a single red target appeared or whether a redsingleton target appeared among three white distractors. Hence, an attentional set for onset appears to be a necessary precondition for the generation of inhibition of return by onset cues. ${ }^{3}$

Our conclusion that task demands can affect the occurrence of inhibition of return is important, because it is often assumed in this field of research that the mere presentation of an onset cue will guarantee the generation of inhibition of return regardless of the nature of the ensuing target display. Indeed, various task manipulations have played an important role in previous investigations into the nature of inhibition of return (see, e.g., Taylor \& Klein, 1998, for a review). The present results thus serve as a warning that task demands may affect the manifestation of inhibition of return by altering the relation between attentional control settings and the inducing stimulus (i.e., onset cues).

The second issue we addressed was whether inhibition of return could be caused by color cues when observers were also intentionally looking for color-defined targets. Unlike the pattern observed with onset cues, the results of Experiment 1 show that color cues were unable to cause inhibition of return regardless of attentional control settings, since significant amounts of inhibition failed to be observed in either the color-target or the onset-target conditions (see Kwak \& Egeth, 1992; Law, Pratt, \& Abrams, 1995). A similar pattern of results was observed in Experiments 2, 3, and 4 across a wider range of conditions. Hence, although abrupt visual onsets do not appear to play a special role in eliciting exogenous attention (Folk et al., 1992; see also Experiment 1 above), they do appear to play a special role in eliciting inhibition of return.

Of course, further experiments will be required in order to determine whether color cues can generate observable amounts of inhibition of return under other stimulus 
and/or task conditions. With respect to stimulus conditions, note that in the present study, the color cues involved a luminance change at each of the four possible locations. Such an arrangement was necessary to dissociate the potential effects of color from the potential effects of luminance or change (see, also, Folk et al., 1992; Gibson \& Kelsey, 1998). Although this arrangement did not appear to impair the ability of the color cues to attract attention, it may nevertheless have impaired the ability to generate inhibition of return. With respect to task conditions, it should be noted that in the majority of previous inhibition of return experiments simple detection tasks or choice localization tasks have been used as opposed to the choice identification task used in the present study (see Taylor \& Klein, 1998). Although the effects of onsetinduced inhibition of return were observed within the context of the choice identification task, the possibility remains that the effects of color-induced inhibition of return may be observed only within the context of more traditional detection or localization tasks.

The final issue we addressed concerned the question of what is inhibited by inhibition of return. The occurrence of inhibition of return within the context of a choice identification task (as was observed in the onset-cue/onsettarget condition) has recently been interpreted as suggesting that covert visual attention may be inhibited, at least in part, by the operation of inhibition of return (Pratt et al., 1997; see also Kingstone \& Pratt, 1999). In this view, inhibition of return is thought to inhibit exogenous visual attention from returning to previously attended locations or objects. Of course, if inhibition of return does reflect the inhibition of exogenous attention, the occurrence of inhibition of return should have a strong tendency to covary with the occurrence of exogenous attentional orienting (Reuter-Lorenz et al., 1996). The findings we obtained with onset cues are consistent with this expectation, since both exogenous attentional orienting and inhibition of return were similarly affected by attentional control settings.

However, other findings obtained in the present study showed that the occurrence of inhibition of return does not always covary with the occurrence of exogenous attentional orienting. In particular, as mentioned above, inhibition of return failed to be established by color cues, regardless of whether these cues were consistent with current attentional control settings or not. Of particular interest was the fact that inhibition of return failed to be established in the color-cue/color-target condition even though the color cues did summon attention. It should be noted that Posner and Cohen (1984; see also Rafal, Calabresi, Brennan, \& Sciolto, 1989) also demonstrated a dissociation between attentional orienting and inhibition of return when attention was allocated endogenously on the basis of a predictive arrow cue. In the present study, we observed a similar dissociation between attentional orienting and inhibition of return even though attention was oriented exogenously in response to an unpredictive color cue. Hence, inhibition of return does not appear to simply reflect the inhibition of exogenous attentional orienting.

How then might we understand the complex pattern of associations and dissociations between exogenous attentional orienting and inhibition of return? On the one hand, the associations between onset-induced attentional orienting and inhibition of return might have occurred because both processes appear to share a common locus in the superior colliculus of the midbrain. For instance, the ability of an onset cue to elicit both early facilitation and late inhibition when onset-defined targets are shown is diminished in patients with degenerative diseases of the midbrain, such as progressive supranuclear palsy (Posner et al., 1985; Rafal, 1996; Rafal \& Henik, 1994; see, also, Danziger, Fendrich, \& Rafal, 1997; Dorris, Taylor, Klein, \& Munoz, 1998). In addition, the early facilitation and late inhibition that are typically induced by onset cues also show asymmetric visual hemifield effects, in accordance with the known anatomy of the midbrain (Rafal et al., 1989; Rafal, Henik, \& Smith, 1991). Hence, although the present results are consistent with the notion that onset-induced attentional orienting is inhibited by inhibition of return, the association may have occurred simply because both processes are mediated by a common orienting network in the brain (i.e., the "posterior network"; see Posner \& Petersen, 1990; and cf. Rafal et al., 1989). For now we can only conclude that attentional control settings do modulate the amount of early facilitation and late inhibition that is generated by an onset cue, which is perhaps due to the gating of the amount of activation that is generated in the midbrain by a luminance transient.

On the other hand, the dissociations between colorinduced attentional orienting and inhibition of return may have occurred because this form of attentional orienting is not mediated by the midbrain. Indeed, evidence is accumulating that suggests that other, more anterior, networks in the brain (involving the basal ganglia) may mediate spatial shifts of covert attention when other types of stimuli, such as symbolic cues, are used to elicit attention (Jackson, Marrocco, \& Posner, 1994). This conclusion is also supported by evidence that shows that this form of attentional orienting is less impaired than onset-induced attentional orienting in patients with progressive supranuclear palsy (Rafal, 1996). As mentioned above, inhibition of return does not occur in response to central, symbolic cues. Thus, attentional orienting and inhibition of return may covary only when both processes are mediated by the midbrain, though there are undoubtedly other factors that may cause them to become dissociated, even if both are mediated by the midbrain (see, e.g., Gibson \& Egeth, 1994; Pratt et al., 1997). Nevertheless, the dissociation between attentional orienting and inhibition of return in the color-cue/color-target condition of the present study may indicate that color-induced exogenous attention is not mediated by the midbrain. Such a conclusion would have important implications for current models of attentional orienting in the brain (Posner \& Petersen, 
1990). Further studies explicitly designed to test this hypothesis are currently being conducted.

\section{REFERENCES}

DANZiger, S., FENDRICH, R., \& RAFAL, R. (1997). Inhibitory tagging of locations in the blind field of hemianopic patients. Consciousness \& Cognition, 6, 291-307.

Dorris, M. C., TAYlor, T., Klein, R., \& Munoz, D. P. (1998, April). Neural correlate of inhibition of return (IOR): Visual and motor preparatory signals in the monkey superior colliculus $(S C)$. Poster presented at the meeting of the Cognitive Neuroscience Society, San Francisco.

Folk, C. L., Remington, R. W., \& Johnston, J. C. (1992). Involuntary covert orienting is contingent on attentional control settings. Journal of Experimental Psychology: Human Perception \& Performance, 18, 1030-1044.

FolK, C. L., Remington, R. W., \& Wright, J. H. (1994). The structure of attentional control: Contingent attentional capture by apparent motion, abrupt onset, and color. Journal of Experimental Psychology: Human Perception \& Performance, 20,317-329.

GiBson, B. S., \& EGETH, H. (1994). Inhibition and disinhibition of return: Evidence from temporal order judgments. Perception \& Psychophysics, 56, 669-680.

GiBSon, B. S., \& JiANG, Y. (1998). Surprise! An unexpected color singleton does not capture attention in visual search. Psychological Science, 9, 176-182.

Gibson, B. S., \& KeLSEY, E. M. (1998). Stimulus-driven attentional capture is contingent on attentional set for displaywide visual features. Journal of Experimental Psychology: Human Perception \& Performance, 24, 699-706.

JACKSON, S. R., MARrocCo, R., \& Posner, M. I. (1994). Networks of anatomical areas controlling visuospatial attention. Neural Networks, 7, 925-944.

Kingstone, A., \& PratT, J. (1999). Inhibition of return is composed of attentional and oculomotor process. Perception \& Psychophysics, 61, 1046-1054.

Klein, R. M., \& TAYLOR, T. L. (1994). Categories of cognitive inhibition with reference to attention. In D. Dagenbach \& T. H. Carr (Eds.), Inhibitory processes in attention, memory, and language (pp. 113147). San Diego, CA: Academic Press.

KWAK, H., \& EGETH, H. (1992). Consequences of allocating attention to locations and to other attributes. Perception \& Psychophysics, 51, 455-464.

Law, M. B., Pratt, J., \& Abrams, R. A. (1995). Color-based inhibition of return. Perception \& Psychophysics, 57, 402-408.

POSNER, M. I., \& COHEN, Y. (1984). Components of visual orienting. In H. Bouma \& D. G. Bouwhuis (Eds.), Attention and performance $X$ (pp. 531-556). Hillsdale, NJ: Erlbaum.

Posner, M. I., \& Petersen, S. E. (1990). The attention system of the human brain. Annual Review of Neuroscience, 13, 25-42.

Posner, M. I., Rafal, R. D., Choate, L. S., \& Vaughan, J. (1985). Inhibition of return: Neural basis and function. Cognitive Neuropsychology, 2, 211-228.

PRATT, J. (1995). Inhibition of return in a discrimination task. Psychonomic Bulletin \& Review, 2, 117-120.

Pratt, J., Kingstone, A., \& KhOE, W. (1997). Inhibition of return in location- and identity-based choice decision tasks. Perception \& Psychophysics, 59, 964-971.

RAFAL, R. [D.] (1996). Visual attention: Converging operations from neurology and psychology. In A. F. Kramer, M. G. H. Coles, \& G. D. Logan (Eds.), Converging operations in the study of visual selective attention (pp. 139-192). Washington, DC: American Psychological Association.

Rafal, R. D., Calabresi, P. A., Brennan, C. W., \& Sciolto, T. K. (1989). Saccade preparation inhibits reorienting to recently attended locations. Journal of Experimental Psychology: Human Perception \& Performance, 15, 673-685.

Rafal, R. [D.], \& Henik, A. (1994). The neurology of inhibition: Integrating controlled and automatic processes. In D. Dagenbach \& T. H. Carr (Eds.), Inhibitory processes in attention, memory, and language (pp. 1-44). San Diego, CA: Academic Press.

RAFAL, R. [D.], HENIK, A., \& SMITH, J. (1991). Extrageniculate contributions to reflex visual orienting in normal humans: A temporal hemifield advantage. Journal of Cognitive Neuroscience, 3, 322-328.

Reuter-Lorenz, P. A., JHA, A. P., \& Rosenquist, J. N. (1996). What is inhibited in inhibition of return? Journal of Experimental Psychology: Human Perception \& Performance, 22, 367-378.

TAYLOR, T. L., \& KLEIN, R. M. (1998). On the causes and effects of inhibition of return. Psychonomic Bulletin \& Review, 5, 625-643.

Terry, K. M., Valdes, L. A., \& NeIll, W. T. (1994). Does "inhibition of return" occur in discrimination tasks? Perception \& Psychophysics, 55, 279-286.

YANTIS, S. (1996). Attentional capture in vision. In A. F. Kramer, M. G. H. Coles, \& G. D. Logan (Eds.), Converging operations in the study of visual selective attention (pp. 45-76). Washington, DC: American Psychological Association.

\section{NOTES}

1. Note that the onset cues used by Folk et al. (1992) differed from those that we used. In the Folk et al. study, onset cues involved the sudden appearance of several dots that were arrayed around a single display location. Thus, the onset cues used by Folk et al. likely involved the appearance of new objects, whereas the onset cues we used likely did not. Although such differences could turn out to be important, for the purposes of the present study, we have assumed that these differences will be only minor. As will become clear in the text below, the results obtained in the short cue-target SOA condition support this assumption.

2. Note that onset-defined target displays should induce a set for onset and that color-defined target displays should induce an attentional set for color, because both onset and color provide target-specific information in their respective displays. In addition, note that color-defined target displays may also induce an attentional set for onset, because onset signals the appearance of the task-relevant target display as a whole in these displays and therefore provides displaywide information (see, e.g., Gibson \& Kelsey, 1998). However, although there is some reason to hypothesize that the color-defined target displays we have used may have induced a displaywide attentional set for onset, there is currently no evidence that attention orients to onset cues when they precede these displays (Folk et al., 1992), perhaps, because the target-specific color information somehow overrides the display-wide onset information (Gibson \& Kelsey, 1998). Thus, because there is currently no evidence that subjects maintain a displaywide attentional set for onset in the color-target condition, only the target-specific attentional set for color is considered in the color-target condition of the present study. Nevertheless, the effect of onset cues in the color-target condition should be interpreted with caution.

3. Of course, it is worth pointing out that an attentional set for onset may not be sufficient for generating inhibition of return, even when onset cues are shown. As mentioned in Note 2, an attentional set for onset may vary in strength depending on the context in which it occurs. Thus, onset cues may fail to generate inhibition of return when observers are only weakly set for onset (as, for instance, in the color-target condition). Moreover, as mentioned in the main text, other factors such as the number of display elements (see, e.g., Pratt et al., 1997) may also affect the generation of inhibition of return even when observers are strongly set for onset (as in the onset-target condition).

(Manuscript received November 23, 1998; revision accepted for publication April 15, 1999.) 